\title{
Is There a Difference in The "Out-Of-Pocket" Costs of Cancer Treatment When Comparing Patients From The Brazilian National Health System With Patients Enrolled in Clinical Research Protocols?
}

Thiago Artioli ( $\nabla$ thiago.artioli48@gmail.com )

Medical Faculty of the ABC: Faculdade de Medicina do ABC https://orcid.org/0000-0001-6242-0885

Karine Corcione Turke

Medical Faculty of the ABC: Faculdade de Medicina do ABC

Aline Hernandez Marquez Sarafyan

Medical Faculty of the ABC: Faculdade de Medicina do ABC

Beatriz Boos Ortolani

Medical Faculty of the ABC: Faculdade de Medicina do ABC Ingrid Victoria Maria Biondo Edle von Schmadel

Medical Faculty of the ABC: Faculdade de Medicina do ABC

Lucas Alves Domiciano Ferreira

Medical Faculty of the ABC: Faculdade de Medicina do ABC

\section{Eduardo Couto Silva}

Medical Faculty of the ABC: Faculdade de Medicina do ABC

Isabel Pinho Mariano da Cruz

Medical Faculty of the ABC: Faculdade de Medicina do ABC

Julye Tainah de Fatima Seminari Pagani

Medical Faculty of the ABC: Faculdade de Medicina do ABC

Pamela dos Santos Monteiro

Medical Faculty of the ABC: Faculdade de Medicina do ABC

Camille Corcione Turke

Medical Faculty of the ABC: Faculdade de Medicina do ABC

Daniel de Iracema Cubero

Medical Faculty of the ABC: Faculdade de Medicina do ABC

Cláudia Vaz de Melo Sette

Medical Faculty of the ABC: Faculdade de Medicina do ABC Auro del Giglio

Medical Faculty of the ABC: Faculdade de Medicina do ABC 


\section{Research Article}

Keywords: Neoplasms, Costs, SUS, Research protocols, Chemotherapy.

Posted Date: September 2nd, 2021

DOl: https://doi.org/10.21203/rs.3.rs-807102/v1

License: (c) (i) This work is licensed under a Creative Commons Attribution 4.0 International License. Read Full License 


\section{Abstract}

\section{Introduction:}

Economic burden of cancer treatment does not fall only on the Brazilian National Health System ("SUS") but also on patients. Nonreimbursed indirect costs include noncovered oral medications, food, transportation, and others. Our study compares out-of-pocket costs of cancer treatment between patients from the SUS and patients enrolled in research protocols.

\section{Methods}

Observational, cross-sectional and analytical study conducted in 2021. Patients undergoing chemotherapy were divided into 2 groups: patients from a tertiary hospital affiliated with the SUS and patients enrolled in research protocols at a research center. The primary outcome was the evaluation of out-of-pocket costs using a socioeconomic questionnaire to identify the cost and time spent by patients during treatment. This study was approved by the Research Ethics Committee.

\section{Results}

195 patients were included, of whom $165(84.6 \%)$ were treated by the SUS and $30(15.4 \%)$ by research protocols. Of the total, $61 \%$ were female, and the mean age of the patients was 57 years. The median total out-of-pocket costs of SUS patients was Brazilian reais (R\$) 453.80 (US\$ 78.92), and that of patients who were enrolled in research protocols was $R \$ 448.00$ (US\$77.91) $(P=0.317)$. A comparison of the groups by multivariate analysis showed that only the time spent by patients on chemotherapy and radiotherapy was significantly different, being higher in the SUS group (OR 2.58, 95\% $\mathrm{Cl} 1.03-6.50$ ).

\section{Conclusion}

Total out-of-pocket spending by SUS patients is similar in magnitude to that by patients in research protocols, although the reasons for the spending are different.

\section{Introduction}

The World Health Organization (WHO), through the International Agency for Research on Cancer, reports that in 2020, more than 19 million new cases of cancer were recorded worldwide, considering all ages and sexes [1]. In addition, projections indicate that cancer will become the leading cause of death in the world, surpassing cardiovascular disease [2]. The increased incidence of cancer reflects a combination of factors, such as population growth and aging, in addition to social and economic development [3]. 
Coupled with the increased incidence of cancer is an increase in the direct cost of the disease, which involves prevention, diagnosis, treatment and follow-up [4]. In Brazil, between 1999 and 2015, spending related only to cancer treatment increased from R\$ 470 million (US\$ 81.7 million) to R\$ 3.3 billion (US\$ 573.9 million) [5]. In the United States in 2020, cancer was the second highest health cost, behind only cardiovascular disease [6].

Although the Brazilian National Health System (SUS, acronym in Portuguese) and other cancer research institutions can fully fund the treatment of patients with cancer [7], the economic burden of the disease also includes additional costs for patients, which increases their financial concerns and that of their relatives [8]. These costs, called indirect or out-of-pocket costs [9], can be basic, for example, transportation, food and medications for symptom control, or complex, for example, economic losses related to loss of income due to treatment. The analysis of the out-of-pocket costs of cancer treatment is extremely important because these costs can be extremely burdensome and can reduce the quality of life of patients and their caregivers during and after treatment [6].

Despite the magnitude of out-of-pocket costs, there is still little description in the literature of the components making up these costs and the impact on these costs when comparing patients covered by the SUS and by research protocols [6]. Thus, the aim of our study is to characterize and investigate the differences between the out-of-pocket costs of patients undergoing cancer treatment, comparing such costs between patients in the SUS and those enrolled in research protocols.

\section{Methods}

\section{Study design}

This is a cross-sectional study that evaluates the out-of-pocket costs of patients undergoing cancer treatment, comparing patients covered by the SUS and patients enrolled in research protocols. We created a database with data from questionnaires answered by patients between November 2020 and February 2021. The study was conducted at Hospital das Clínicas de São Bernardo do Campo and at the Research Center for Hematology and Oncology (CEPHO, acronym in Portuguese), both associated services of the University Center of the School of Medicine of the ABC (FMABC, acronym in Portuguese) located in Santo André, São Paulo, Brazil.

\section{Participants}

Nonselected patients older than 18 years with a confirmed diagnosis of malignant neoplasia who were undergoing active cancer treatment (chemotherapy and/or radiotherapy), who adequately completed the questionnaires, and who agreed to participate in the study by signing the informed consent form were included in the study. Patients were included at 2 locations:

- Patients treated through the SUS at Hospital das Clínicas de São Bernardo do Campo; and

- Patients enrolled in research protocols at CEPHO. 
If the patients met the inclusion criteria, no exclusion criteria were applied.

\section{Questionnaires and study variables}

Our cross-sectional study was based on the application of 2 questionnaires. The epidemiological characteristics of the patients were obtained from the first applied questionnaire. It included demographic data such as sex, age, race, marital status, education level, occupation, origin, comorbidities and medications used and socioeconomic factors such as type of occupation, monthly income, housing and transportation.

The cost-time questionnaire was the second applied questionnaire and included an evaluation of the amounts spent on transportation, medications, food and supplies and the minutes or hours spent on activities related to cancer treatment not covered by the SUS. With this questionnaire, we calculated the costs not covered by the SUS or by research protocols (known as indirect or out-of-pocket costs) of patients with cancer incurred during treatment. The currency considered in the questionnaires was the Brazilian real ( $R \$)$, and the Brazilian minimum wage in 2021 was used as the unit of measurement. The values in Brazilian reais were then converted into US dollars (US\$) based on the exchange rate in February 2021 (R\$ $5.75=$ US\$ 1.00), the date of the final data collection.

The following points explain how the variables were calculated in Brazilian reais:

- Time: We converted time into money by calculating the mean hourly wage based on the mean number of minimum wages received by patients, number of days in the month and hours of work per month. We assumed that the work week was a maximum of 40 hours and that individuals worked 4 weeks per month. Hours were converted into reais so that we could represent the hours spent as part of the total additional costs.

- Transportation: For patients who used a car, the cost was calculated as the product of the distance (in kilometers) from their residence to certain places (hospital, pharmacy and health center) and the cost of the fuel used in 2021 in Brazil. In the case of public transportation (bus, alternative transport), the cost considered was the transport fare multiplied by the number of trips; for taxis, the cost considered was the amount charged by the driver for each trip; and for cyclists or for those who walked, no expense was calculated.

- Medications: Only the costs of the medications acquired by the patient were added; those provided by health units were not counted. For the calculation, the patient provided the medication name, dosage and amount used per month. For supplies, patients named the supplies and listed the amount spent in the last month related to treatment.

\section{Definition of study outcomes}

The primary outcome chosen to compare patients from the different groups (SUS vs. research protocols) was the total out-of-pocket costs in Brazilian reais. The secondary analysis included stratified variables of the cost-time questionnaire, comparing the 2 groups. 


\section{Ethics committee approval}

The study was conducted in accordance with the principles of the Declaration of Helsinki [10]. The study protocol was approved by the Research Ethics Committee of FMABC University Center (approval number: 30524420.3.0000.0082).

We adhered to the STROBE guidelines for observational studies (Supplementary Table 1) [11].

\section{Statistical analysis}

The questionnaire responses were collected and tabulated in an anonymous fashion in Microsoft Excel, creating a database, and the data were subsequently subjected to statistical analysis. Categorical variables are presented as numbers and percentages (frequencies) and were analyzed using Fisher's exact test. Continuous variables are presented as means and standard deviations or as medians and interquartile ranges depending on normality, as determined by the Shapiro-Wilk test. Normal continuous variables were analyzed by Student's t-test. Nonnormally distributed continuous variables were analyzed using the Mann-Whitney test.

For the multivariate analysis, we calculated the $95 \%$ confidence intervals $(95 \% \mathrm{Cls})$ and $\mathrm{P}$ values using multivariate logistic regression to adjust for confounding variables. Clinical, demographic and socioeconomic variables significant in the univariate analysis were included in the multivariate model. Based on the number of events and the consensus of 10 events for each independent variable, we considered all variables with $\mathrm{P}<0.05$ in the univariate analysis.

The level of significance was set at $95 \%(P<0.05)$. Statistical analyses were performed using $R(R$ Core Team, 2020 - R: A language and environment for statistical computing. R Foundation for Statistical Computing, Vienna, Austria. URL https://www.R-project.org/).

\section{Results}

\section{Sociodemographic characteristics of the study population}

Between November 2020 and February 2021, 195 participants were included in the study (Table 1). Among the 195 patients, 165 were in the SUS group, and 30 were in the research protocol (RP) group. The mean age of patients in the SUS group was $56 \pm 11$ years, and the mean age of patients in the RP group was $60 \pm 14$ years. In the SUS group, 106 (64.2\%) were female, and 59 (35.8\%) were male; in the RP group, $13(43.3 \%)$ were female, and $17(56.7 \%)$ were male. Hypertension and diabetes were the most prevalent comorbidities in both groups.

Regarding cancer treatment through the SUS, cancer affecting the breast as the primary organ was the most frequent, present in 40 patients $(24.2 \%)$, followed by gastrointestinal (large intestine) cancer in 28 patients (17\%). In this same group, most participants had been diagnosed with cancer less than 1 year prior $(60.6 \%)$ and had no need to undergo radiotherapy as treatment (73.3\%). In the RP group, breast 
(30\%) and prostate (16.7\%) cancer were the most prevalent, with only $20 \%$ of patients diagnosed less than 1 year prior and $76.7 \%$ with no need for radiotherapy. 
Table 1

Sociodemographic and clinical characteristics of the 195 patients undergoing cancer treatment.

$\begin{array}{llll}\text { All patients } & \text { SUS } & \begin{array}{l}\text { Research } \\ \text { protocols }\end{array} & \begin{array}{l}\text { P- } \\ \text { value }\end{array} \\ n=195 & n=165 & n=30 & \\ n(\%) & n(\%) & n(\%) & \end{array}$

Sex

Female

$119(61 \%) \quad 106$

$(64.2 \%)$

$13(43.3 \%)$

0.041

Male

$76(38.9 \%) \quad 59(35.8 \%) \quad 17(56.7 \%)$

Age (mean \pm standard deviation)

$57 \pm 12$

$56 \pm 11$

$60 \pm 14$

0.130

\section{Ethnicity}

Non-white

$78(40 \%)$

$64(61.2 \%)$

$14(46.7 \%)$

0.426

White

$117(60 \%)$

101

(38.8\%)

$16(53.3 \%)$

\section{Marital status}

\section{Single}

Married

Divorced

Widowed

Education level

Illiterate

Incomplete primary

Complete primary

Incomplete secondary

Complete secondary

Incomplete higher

Complete higher

Occupation

Employed
$38(19.5 \%) \quad 35(21.2 \%) \quad 3(10 \%)$

0.154

110

(56.4\%)

$87(52.7 \%) \quad 23(76.6 \%)$

$24(12.3 \%) \quad 22(13.3 \%) \quad 2(6.7 \%)$

$23(11.8 \%) \quad 21(12.7 \%) \quad 2(6.7 \%)$ 


\begin{tabular}{|c|c|c|c|c|}
\hline & $\begin{array}{l}\text { All patients } \\
n=195 \\
n(\%)\end{array}$ & $\begin{array}{l}\text { SUS } \\
n=165 \\
n(\%)\end{array}$ & $\begin{array}{l}\text { Research } \\
\text { protocols } \\
n=30 \\
n(\%)\end{array}$ & $\begin{array}{l}\mathrm{P} \text { - } \\
\text { value }\end{array}$ \\
\hline Unemployed & $67(33.8 \%)$ & $62(37.5 \%)$ & $5(16.7 \%)$ & \\
\hline Retired & $60(30.8 \%)$ & $47(28.5 \%)$ & $13(43.3 \%)$ & \\
\hline \multicolumn{5}{|l|}{ Alcohol consumption } \\
\hline Yes & $15(7.7 \%)$ & $14(8.5 \%)$ & $1(3.3 \%)$ & 0.475 \\
\hline \multicolumn{5}{|l|}{ Smoking } \\
\hline Smoker & $16(8.2 \%)$ & $16(9.7 \%)$ & $0(0 \%)$ & \multirow[t]{2}{*}{0.154} \\
\hline Former smoker & $78(40 \%)$ & $63(38.2 \%)$ & $15(50 \%)$ & \\
\hline \multicolumn{5}{|l|}{$\begin{array}{l}\text { Medications used (excluding cancer } \\
\text { medications) }\end{array}$} \\
\hline 1 medication & $49(25.1 \%)$ & $41(24.8 \%)$ & $8(26.7 \%)$ & \multirow[t]{3}{*}{0.919} \\
\hline 2 medications & $40(20.5 \%)$ & $34(20.6 \%)$ & $6(20 \%)$ & \\
\hline$\geq 3$ medications & $45(23.1 \%)$ & $37(22.4 \%)$ & $8(26.7 \%)$ & \\
\hline \multicolumn{5}{|l|}{ Comorbidities } \\
\hline Hypertension & $66(33.8 \%)$ & $54(32.7 \%)$ & $12(40 \%)$ & 0.529 \\
\hline Diabetes & $27(13.8 \%)$ & $21(12.7 \%)$ & $6(20 \%)$ & 0.386 \\
\hline Dyslipidemia & $7(3.6 \%)$ & $7(4.2 \%)$ & $0(0 \%)$ & 0.598 \\
\hline Depression & $7(3.6 \%)$ & $6(3.6 \%)$ & $1(3.3 \%)$ & 1.0 \\
\hline \multirow[t]{2}{*}{ BMI (median, interquartile range) } & 26.45 & 26.02 & 27.4 & \multirow[t]{2}{*}{0.041} \\
\hline & $\begin{array}{l}(23.18- \\
30.47)\end{array}$ & $\begin{array}{l}(22.95- \\
30.22)\end{array}$ & $(25.64-31.24)$ & \\
\hline \multicolumn{5}{|l|}{ Home } \\
\hline Owned & $\begin{array}{l}140 \\
(71.8 \%)\end{array}$ & $\begin{array}{l}119 \\
(72.1 \%)\end{array}$ & $21(70 \%)$ & \multirow[t]{3}{*}{$\begin{array}{l}<.001 \\
0.00\end{array}$} \\
\hline Rented & $41(21 \%)$ & 39 (23.6\%) & $2(6.7 \%)$ & \\
\hline Financed & $14(7.2 \%)$ & $7(4.2 \%)$ & $7(23.3 \%)$ & \\
\hline
\end{tabular}

SUS: National Health System; BMI = body mass index. 


\begin{tabular}{|c|c|c|c|c|}
\hline & $\begin{array}{l}\text { All patients } \\
n=195 \\
n(\%)\end{array}$ & $\begin{array}{l}\text { SUS } \\
n=165 \\
n(\%)\end{array}$ & $\begin{array}{l}\text { Research } \\
\text { protocols } \\
n=30 \\
n(\%)\end{array}$ & $\begin{array}{l}\mathrm{P} \text { - } \\
\text { value }\end{array}$ \\
\hline Large intestine & $28(14.4 \%)$ & $28(17 \%)$ & $0(0 \%)$ & \multirow[t]{7}{*}{0.003} \\
\hline Breast & $49(25.1 \%)$ & $40(24.2 \%)$ & $9(30 \%)$ & \\
\hline Prostate & $7(3.6 \%)$ & $2(1.2 \%)$ & $5(16.7 \%)$ & \\
\hline Cervix & $4(2.1 \%)$ & $4(2.4 \%)$ & $0(0 \%)$ & \\
\hline Liver & $8(4.1 \%)$ & $6(3.6 \%)$ & $2(6.7 \%)$ & \\
\hline Lung & $4(2.1 \%)$ & $3(1.8 \%)$ & $1(3.3 \%)$ & \\
\hline Other & $29(14.9 \%)$ & $27(16.4 \%)$ & $2(6.7 \%)$ & \\
\hline \multicolumn{5}{|c|}{ Time since diagnosis } \\
\hline$\otimes 6 \mathrm{~m}$ & $48(24.6 \%)$ & $43(26.1 \%)$ & $5(16.7 \%)$ & \multirow{3}{*}{$\begin{array}{l}< \\
0.00\end{array}$} \\
\hline $6-12 m$ & $58(29.7 \%)$ & 57 (34.5\%) & $1(3.3 \%)$ & \\
\hline$>12 \mathrm{~m}$ & $83(42.6 \%)$ & $63(38.2 \%)$ & $20(66.7 \%)$ & \\
\hline \multicolumn{5}{|l|}{ Radiotherapy } \\
\hline Yes & $51(26.2 \%)$ & $44(26.7 \%)$ & $7(23.3 \%)$ & \multirow[t]{2}{*}{0.823} \\
\hline No & $\begin{array}{l}144 \\
(73.8 \%)\end{array}$ & $\begin{array}{l}121 \\
(73.3 \%)\end{array}$ & $23(76.7 \%)$ & \\
\hline
\end{tabular}

\section{Cost-time questionnaire and socioeconomic characteristics}

The median monthly income (in number of minimum wages) of the patients was 1 minimum wage for both groups, with an interquartile range of 1-2.5 minimum wages for the SUS group and 1-4 minimum wages for the RP group. The highest monthly expenditure reported by patients was the same for both the SUS and RP groups: transportation. The SUS group spent a median of R\$100.00 (US \$17.39), with a median of 7 monthly trips related to treatment. The RP group spent a median R\$117.00 (US\$20.35), with a median of 4 monthly treatment-related trips. Another important expense was the number of telephone calls related to cancer treatment, with a median of R\$ 50.00 spent per month (US \$8.70) in the SUS group and a median of R\$ 75.00 spent per month (US\$ 13.04) in the RP group.

The most amount of time spent by patients in cancer treatment was the monthly hours spent in chemotherapy or radiotherapy, with a median of 8 hours (IQR 6.0-12.0) in the SUS group and 4 hours 
(IQR 0.0-12.0) in the RP group. The data calculated from the cost-time questionnaire are provided in Table 2. 
Table 2

Cost-time questionnaire: impact of costs on patients undergoing cancer treatment.

\begin{tabular}{|c|c|c|c|c|}
\hline & $\begin{array}{l}\text { All patients } \\
n=195\end{array}$ & $\begin{array}{l}\text { SUS } \\
n=165\end{array}$ & $\begin{array}{l}\text { Research } \\
\text { protocols } \\
n=30\end{array}$ & $\begin{array}{l}\mathrm{P}- \\
\text { value }\end{array}$ \\
\hline $\begin{array}{l}\text { Monthly income } \\
\text { (n of minimum wages) }\end{array}$ & $1.0(1.0-2.5)$ & $1.0(1.0-2.5)$ & $1.0(1.0-4.0)$ & 0.026 \\
\hline \multicolumn{5}{|l|}{ Means of transport } \\
\hline Own car & $163(83.6 \%)$ & $138(83.6 \%)$ & $25(83.3 \%)$ & \multirow[t]{2}{*}{1.0} \\
\hline Public & $32(16.4 \%)$ & $27(16.4 \%)$ & $5(16.7 \%)$ & \\
\hline Number of trips & $7.0(4.0-10.0)$ & $7.0(5.0-12.0)$ & $4.0(2.25-8.0)$ & 0.003 \\
\hline Spending on transportation (US\$) & $\begin{array}{l}17.39 \\
(2.96-39.13)\end{array}$ & $\begin{array}{l}13.91 \\
(1.74-41.74)\end{array}$ & $\begin{array}{l}20.35 \\
(9.57-34.78)\end{array}$ & 0.230 \\
\hline General food expenditure (US\$) & $0.0(0.0-5.57)$ & $0.0(0.0-5.22)$ & $2.09(0.0-6.74)$ & 0.093 \\
\hline Hotel stay (US\$) & $0(0.0-0.0)$ & $0(0.0-0.0)$ & $0(0.0-0.0)$ & NA \\
\hline Spending on phone (US\$) & $\begin{array}{l}9.91(4.78- \\
14.43)\end{array}$ & $\begin{array}{l}8.70(3.48- \\
13.74)\end{array}$ & $\begin{array}{l}13.04(8.35- \\
22.17)\end{array}$ & 0.012 \\
\hline $\begin{array}{l}\text { Spending on private medication } \\
\text { (US\$) }\end{array}$ & $\begin{array}{l}0.52(0.0- \\
17.39)\end{array}$ & $\begin{array}{l}2.26(0.0- \\
17.39)\end{array}$ & $0.0(0.0-10.13)$ & 0.066 \\
\hline $\begin{array}{l}\text { Spending on alternative therapies } \\
\text { (US\$) }\end{array}$ & $0(0.0-0.0)$ & $0(0.0-0.0)$ & $0(0.0-0.0)$ & NA \\
\hline Time spent on consultations (hours) & $1.0(2.0-4.0)$ & $2.0(1.0-4.0)$ & $1.0(0.5-6.5)$ & 0.345 \\
\hline Time spent on CT/RT (hours) & $8.0(5.0-12.0)$ & $8.0(6.0-12.0)$ & $4.0(0.0-12.0)$ & $\hat{L}_{0.001}$ \\
\hline $\begin{array}{l}\text { Time spent purchasing medication } \\
\text { (minutes) }\end{array}$ & $\begin{array}{l}15.0(0.0- \\
30.0)\end{array}$ & $\begin{array}{l}20.0(0.0- \\
30.0)\end{array}$ & $5.5(0.0-20.0)$ & 0.052 \\
\hline Time spent on other activities (hours) & $0.0(0.0-1.0)$ & $0.0(0.0-0.5)$ & $0.25(0.0-2.75)$ & 0.006 \\
\hline Hourly cost per individual (US\$) & $\begin{array}{l}1.20(1.20- \\
2.99)\end{array}$ & $\begin{array}{l}1.20(1.20- \\
2.99)\end{array}$ & $\begin{array}{l}2.99(1.20- \\
4.78)\end{array}$ & 0.026 \\
\hline $\begin{array}{l}\text { Cost-time spent on consultations } \\
\text { (US\$) }\end{array}$ & $\begin{array}{l}2.99(0.61- \\
9.57)\end{array}$ & $\begin{array}{l}2.99(0.60- \\
7.17)\end{array}$ & $\begin{array}{l}2.69(1.20- \\
28.25)\end{array}$ & 0.345 \\
\hline Cost-time spent on CT/RT (US\$) & $\begin{array}{l}14.35 \\
(3.59-29.59)\end{array}$ & $\begin{array}{l}14.35 \\
(4.78-28.70)\end{array}$ & $\begin{array}{l}9.57 \\
(0.0-32.28)\end{array}$ & 0.185 \\
\hline
\end{tabular}




\begin{tabular}{|lllll|}
\hline & All patients & SUS & $\begin{array}{l}\text { Research } \\
\text { protocols } \\
\mathrm{n}=195\end{array}$ & $\begin{array}{l}\text { P- } \\
\text { value }\end{array}$ \\
\hline $\begin{array}{l}\text { Cost-time spent purchasing } \\
\text { medications (US\$) }\end{array}$ & $\begin{array}{l}0.40(0.0- \\
0.90)\end{array}$ & $\begin{array}{l}0.40(0.0- \\
0.90)\end{array}$ & $0.13(0.0-0.71)$ & 0.464 \\
\hline $\begin{array}{l}\text { Cost-time spent on other activities } \\
\text { (US\$) }\end{array}$ & $0(0.0-0.0)$ & $0(0.0-0.0)$ & $0.0(0.0-4.48)$ & N/A \\
\hline Total cost (US\$) & 78.92 & 78.92 & 77.91 & 0.317 \\
& $(42.35-$ & $\begin{array}{l}(41.90- \\
155.80)\end{array}$ & $(50.57-195.44)$ & \\
\hline
\end{tabular}

Numerical variables are presented as medians and interquartile ranges (non-parametric distribution). The values were converted from reais to dollars, as explained in the methods section. SUS $=$ National Health System; CT = chemotherapy; $\mathrm{RT}$ = radiotherapy.

\section{Primary outcome: total out-of-pocket costs}

In the SUS group, the interquartile range for the total monthly out-of-pocket expenditure by patients was $\mathrm{R} \$ 240.90-895.90$ (US\$ 41.90-155.81), with a median of R\$ 453.8 (US\$ 78.92). In the RP group, the interquartile range for the total monthly out-of-pocket expenditure by patients was $\mathrm{R} \$ 290.80-1123.80$ (US\$ 50.57-195.44), with a median of R\$ 448.00 (US\$ 77.91). In the univariate analysis, there was no significant difference between the total out-of-pocket expenditure when comparing the SUS and RP groups $(P=0.317)$.

After adjusting for confounders in the multivariate analysis (Table 3), only the time spent by patients on chemotherapy and radiotherapy was significantly different, being higher in the SUS group (OR 2.58, 95\% Cl 1.03-6.50, $\mathrm{P}=0.043)$. 
Table 3

Multivariate analysis by binary logistic regression.

\begin{tabular}{|lll|}
\hline & $\begin{array}{l}\text { Adjusted OR } \\
(95 \% \mathrm{Cl})\end{array}$ & P value \\
\hline Treatment center & & \\
\hline Female sex & $12.67(0.0-$ inf $)$ & 0.999 \\
\hline Time since diagnosis & & \\
\hline 6-12 months & $0.037(0.0-3.47)$ & 0.155 \\
\hline$>12$ months & $0.213(0.01-4.33)$ & 0.315 \\
\hline Primary organ & & \\
\hline Large intestine & Ref & Ref \\
\hline Breast & $0.0(0.0-$ inf $)$ & 0.999 \\
\hline Prostate & $0.0(0.0-$ inf $)$ & 0.997 \\
\hline Cervix & $0.012(0.0-$ inf $)$ & 0.999 \\
\hline Liver & $297.02(0.0-$ inf $)$ & 0.999 \\
\hline Lung & $0.279(0.0-$ inf $)$ & 1.0 \\
\hline Home & & \\
\hline Rented & $0.176(0.0-7.37)$ & 0.362 \\
\hline Financed & $0.0(0.0-10.37)$ & 0.106 \\
\hline Number of trips & $0.556(0.29-1.08)$ & 0.083 \\
\hline Telephone costs & $0.996(0.97-1.02)$ & 0.717 \\
\hline Time spent on CT/RT & $2.586(1.03-6.50)$ & 0.043 \\
\hline Time spent on other & $0.963(0.89-1.05)$ & 0.379 \\
activities & & \\
\hline & & \\
\hline
\end{tabular}

\section{Discussion}

Cancer is an important cause of mortality worldwide, with a trend that seems to only increase. Along with the growth in morbidity and mortality, the economic burden of direct and indirect costs is also increasing. This study aimed to characterize the out-of-pocket costs of cancer treatment incurred by patients during treatment, either through the SUS or research protocols. 
Our study population was mostly female (61\%), with a mean age older than 50 years, findings that are consistent with those in other studies involving patients with cancer $[6,12-19]$. There was greater participation by individuals who reported being white $(60 \%)$, although the majority of the Brazilian population self-reports as black [20]. Based on the literature, the main comorbidities of patients with cancer are hypertension, diabetes and dyslipidemia, consistent with the results of our study [6].

Regarding cancer characteristics, breast cancer is the most prevalent among patients both in our study and in the literature, but the time since diagnosis differs, and in our study, most patients had been diagnosed more than 12 months prior $(42.6 \%)[12,13,20]$.

In the analysis of the total out-of-pocket costs incurred by patients, the mean final value, i.e., $R \$ 453.80$ (US\$ 78.92) per month, was lower than that found in a similar study conducted in the United States, in which the monthly mean was approximately R 1071.00 (based on the dollar exchange rate at the time) [21]. In addition, the total monthly expenditure found in this study was also substantially lower than that found in another study conducted in northern India in which the mean out-of-pocket expenditure by patients with head and neck cancer was R 2123.86 (US\$ 369.37) based on the rupee/real exchange rate in 2019 [14]. This difference may be explained by the type of cancer investigated, indicating that there is a difference in spending not only between different regions but also between different types of cancer.

When comparing our results with the Brazilian reality, 43.4\% (R\$1045.00/US\$181.74) of 1 minimum wage in 2020 was spent by patients on out-of-pocket expenses; however, in another Brazilian study, the total out-of-pocket spending represented $78.4 \%$ of the minimum wage at the time (2018) [6], indicating that even though the value is high, the percentage found in this study was not higher than that in 2018 .

Stratifying the out-of-pocket costs surveyed, the transportation expenditure was the highest, approximately R\$ 100.00 (US\$17.39) per month, a finding similar to that in another Brazilian study and to that in a Canadian review that also found transportation among the top 4 highest expenses for patients with cancer [21]. This finding indicates that transportation to treatment-related commitments (consultations, chemotherapy, radiotherapy, and laboratory tests, among others) is a critical part of outof-pocket costs and, thus, where patients would benefit the most from receiving aid.

No significant difference was found between the SUS and RP groups regarding the means of transportation, and the proportion of patients who used cars or public transportation was similar in each group; however, compared to previous studies conducted in Brazil, in this study, there was an increase in the proportion of patients who used their own car [12]. Despite the similarity in the use of means of transportation and the finding that SUS patients make more trips, the RP patients had a $46.25 \%$ higher mean transportation expenditure. Interestingly, the 2 groups spent more on transportation than did patients in a previous study [17] but less on transportation than did patients in studies from other regions and countries, indicating perhaps greater difficulty in accessing health services in these locations [6, 20]. However, we cannot exclude the roles of inflation and our setting as causes of the differences in transportation costs between studies conducted at different times. 
The results of the multivariate analysis show that there was no significant difference between the SUS and RP groups. This may be due to the balance between some expenses among the evaluated costs. For example, while the RP group spent more on telephones, the SUS group had higher expenses related to the number of trips. Differently from another study conducted on the costs incurred by cancer patients that found that employed patients incurred higher costs, in this study, patient occupation was not significant in determining the difference between costs. In contrast, education level, type of cancer, sex, age and ethnicity were not significant either in our study or in another study conducted in Brazil [6].

Because of the observational nature of our study, the limitations include the impossibility of establishing cause and effect relationships and include the possible presence of biases and confounding factors. Our questionnaires, especially those related to cost-time, required that patients remember various expenses and situations, potentially introducing recall bias. Additionally, the different proportion of patients from the SUS and RP may have influenced the results, but unfortunately, in the context of the COVID-19 pandemic, several patients were lost to follow-up, especially in the RP group. Last, our patient sample represents only a portion of patients undergoing cancer treatment, which includes patients from several other health centers that may have their own patient protocols and services.

\section{Conclusion}

Although research protocols reduce the costs related to cancer treatment for the SUS and other paying sources, there was no impact on the out-of-pocket costs incurred by the patients. These out-of-pocket costs represent an important portion of the costs incurred by patients undergoing cancer treatment through the SUS and those enrolled in research protocols. The data reported here suggest that government aid in the form of a grant of approximately 1 minimum wage for patients diagnosed with cancer in our setting could mitigate these out-of-pocket costs.

\section{Declarations}

\section{Funding}

The authors did not receive support from any organization for the submitted work.

\section{Authors Contribution}

All authors were part in the designing, data collection, data analysis and writing of this article, and all have approved the final version for publication.

\section{Conflicts of Interest}

The authors have no relevant financial or non-financial interests to disclose related to this work.

\section{Availability of Data and Material}


Every available data and material is declared in the manuscript text.

\section{Ethics Approval}

The study was conducted in accordance with the principles of the Declaration of Helsinki [10]. The study protocol was approved by the Research Ethics Committee of FMABC University Center (approval number: 30524420.3.0000.0082).

\section{Consent to Participate}

Written informed consent was obtained from all individual participants included in the study.

\section{Consent for Publication}

Not applicable.

\section{References}

1. World Health Organization. GLOBOCAN 2021. Cancer Today. Disponível em < Cancer Today (iarc.fr)>. Acesso em: 21 de maio de 2021.

2. World Health Organization. Global health observatory data repository (2011) Number of deaths (World) by cause. Available from: http://apps.who.int/gho/data/node.main.CODWORLD?lang=en. Last accessed 30 January 2020

3. World Health Organization. Latest Global Cancer Data (2018) International Agency for Research on Cancer. Available from: https://www.who.int/cancer/PRGlobocanFinal.pdf. Last accessed 2 February 2020

4. Lentz R, Benson AB, Kircher S (2019) Financial toxicity in cancer care: Prevalence, causes, consequences, and reduction strategies. J Surg Oncol 120(1):85-92

5. Setor Saúde. 0 custo de tratamento de câncer no Brasil. 2018. Estatísticas e Análises. Disponível em: https://setorsaude.com.br/o-custo-do-tratamento-do-cancer-no-brasil/. Acessado em: 2 de fevereiro de 2020

6. ARAUJO, José Klerton Luz et al. Assessment of costs related to cancer treatment. Rev. Assoc. Med. Bras., São Paulo, v. 66, n. 10, p. 1423-1430, Oct. 2020. Available from < http://www.scielo.br/scielo.php?script=sci_arttext\&pid=S010442302020001001423\&lng=en\&nrm=iso>. access on 21 May 2021. Epub Nov 06, 2020. https://doi.org/10.1590/1806-9282.66.10.1423.

7. Paim J, Travassos C, Almeida C, Bahia L, Macinko J (2011) The Brazilian health system: history, advances, and challenges. Lancet. May 21;377(9779):1778-97

8. Satibi S, Andayani TM, Endarti D, Suwantara IPT, Agustini NPD (2019) Comparison of real cost versus the Indonesian case base groups (INA-CBGs) tariff rates among patients of high-incidence cancers under the national health insurance scheme. Asian Pac J Cancer Prev 20(1):117-122 
9. Zaremba G et al (2016) Out-of-pocket costs for cancer patients treated at the Brazil- ian public health system (SUS) and for their caregivers: A pilot study. Clinical Oncology Letters 2(1):23-30

10. World Medical Association (2013) World Medical Association Declaration of Helsinki. JAMA 310(20):2191

11. von Elm E, Altman DG, Egger M et al (2007) The Strengthening the Reporting of Observational Studies in Epidemiology (STROBE) statement: guidelines for reporting observational studies. Lancet 370(9596):1453-1457

12. Koskinen J-P, Färkkilä N, Sintonen H, Saarto T, Taari K, Roine RP (2019 Jul) The association of financial difficulties and out-of-pocket payments with health-related quality of life among breast, prostate and colorectal cancer patients. Acta Oncol 3(7):1062-1068 58(

13. Dehghan $M$, Jazinizade $M$, Malakoutikhah A, Madadimahani A, Iranmanesh MH, Oghabian S et al (2020) Stress and Quality of Life of Patients with Cancer: The Mediating Role of Mindfulness. J Oncol 2020:3289521

14. Chauhan AS, Prinja S, Ghoshal S, Verma R (2019 Feb) Economic Burden of Head and Neck Cancer Treatment in North India. Asian Pac J Cancer Prev 26(2):403-409 20(

15. Callahan C, Brintzenhofeszoc K (2015) Financial Quality of Life for Patients With Cancer: An Exploratory Study. J Psychosoc Oncol 33(4):377-394

16. Smith GL, Lopez-Olivo MA, Advani PG, Ning MS, Geng Y, Giordano SH et al (2019) Financial Burdens of Cancer Treatment: A Systematic Review of Risk Factors and Outcomes. J Natl Compr Canc Netw. Oct 1;17(10):1184-92

17. del Giglio A et al (2016) Out-of-pocket costs for cancer patients treated at the Brazilian public health system (SUS) and for their caregivers: A pilot study. Clin Onc Let 2(1):23-30

18. Gordon LG, Merollini KMD, Lowe A, Chan RJ (2017 Jun) A Systematic Review of Financial Toxicity Among Cancer Survivors: We Can't Pay the Co-Pay. Patient 10(3):295-309

19. Zafar SY, Peppercorn JM, Schrag D, Taylor DH, Goetzinger AM, Zhong X et al (2013) The financial toxicity of cancer treatment: a pilot study assessing out-of-pocket expenses and the insured cancer patient's experience. Oncologist 18(4):381-390

20. IBGE EDUCA. Conheça o Brasil - População - Cor ou Raça. Disponível em: https://educa.ibge.gov.br/jovens/conheca-o-brasil/populacao/18319-cor-ou-raca.html. Acesso em: 21 jun. 2021

21. Coumoundouros C, Ould Brahim L, Lambert SD, McCusker J (2019 Sep) The direct and indirect financial costs of informal cancer care: A scoping review. Health Soc Care Community 27(5):e622e636

\section{Supplementary Files}

This is a list of supplementary files associated with this preprint. Click to download. 
- supplementarytable1outofpocketcosts.docx 